\title{
MEASUREMENT OF THE LINEAR DEPOLARIZATION RATIO OF AGED DUST AT THREE WAVELENGTHS (355, 532 AND 1064 nm) SIMULTANEOUSLY OVER BARBADOS
}

\author{
Moritz Haarig $^{1 *}$, Dietrich Althausen ${ }^{1}$, Albert Ansmann ${ }^{1}$, André Klepel ${ }^{1}$, Holger Baars ${ }^{1}$, Ronny \\ Engelmann', Silke Groß ${ }^{2}$, Volker Freudenthaler ${ }^{2}$ \\ ${ }^{1}$ Leibniz Institute for Tropospheric Research (TROPOS), Permoserstr. 15, 04318 Leipzig, Germany, \\ *Email: haarig@tropos.de
}

${ }^{2}$ Meteorological Institute, Ludwig-Maximilians-University, Theresienstr. 37, 80333 Munich, Germany

\begin{abstract}
A ground-based polarization Raman lidar is presented, that is able to measure the depolarization ratio at three wavelengths $(355$, 532 and $1064 \mathrm{~nm}$ ) simultaneously. This new feature is implemented for the first time in a Raman lidar. It provides a full dataset of 3 backscatter coefficients, two extinction coefficients and 3 depolarization ratios $(3+2+3$ lidar system). To ensure the data quality, it has been compared to the well characterized twowavelength polarization lidar POLIS. Measurements of long-range transported dust have been performed in the framework of the Saharan Aerosol Long-Range Transport and Aerosol-Cloud-Interaction Experiment (SALTRACE) in the Caribbean.
\end{abstract}

\section{INTRODUCTION}

Aerosols affect the radiative budget of the Earth. Mineral dust is one major component of the global aerosol load. It demonstrates a high temporally and spatially variability and furthermore the dust may change its properties and size distribution during transport or gets mixed with other species of aerosols. So observation and modelling of the properties and distribution of dust is a challenging task.

Lidar measurements provide vertically resolved profiles of the optical properties of the aerosols, such as the particle backscatter and extinction coefficient and the depolarization ratio. In order to get most detailed information about the dust particles, several wavelengths are used. With this additional spectral information, it will be easier for inversion algorithms to retrieve microphysical properties from the measured optical properties. Especially for dust investigations the aerosol linear depolarization ratio at $1064 \mathrm{~nm}$ is of great benefit (Gasteiger and Freudenthaler, 2014).

In order to provide such an extensive data set, the lidar system BERTHA of the TROPOS has been newly set up. Additionally to the backscatter at three wavelengths and the extinction at two wavelengths, the simultaneously measurement of the linear depolarization ratio at three wavelengths is now implemented.

Long-range transported dust has been observed the this improved lidar system in the Saharan Aerosol Long-Range Transport and AerosolCloud-Interaction Experiment (SALTRACE) on Barbados $\left(13^{\circ} \mathrm{N}, 59^{\circ} \mathrm{W}\right)$ in 2013 (summer) and in 2014 (winter and summer). The campaigns aim to analyze the properties of long-range transported Saharan dust, taking advantage of the fact, that the dust is transported about $5000 \mathrm{~km}$ only over the ocean without pollution or continental influence. In line with the previous campaigns SAMUM-1 (Heintzenberg, 2008) in southern Morocco (2006) and SAMUM-2 (Ansmann et al., 2011) at the Cape Verde (2008), the SALTRACE campaign completes the investigation of the transport way of the dust from the source region in the Sahara to the Caribbean. A measurement example of a dust outbreak will be shown.

\section{LIDAR SYSTEM}

The multi-wavelength polarization Raman lidar BERTHA (Backscatter Extinction lidar-Ratio Temperature Humidity profiling Apparatus) of the Leibniz Institute of Tropospheric Research (TROPOS) is a container-based mobile lidar system. It has been renewed after the SAMUM campaigns and contains a new receiver unit enabling the measurement of the depolarization at three wavelengths simultaneously. Furthermore a 
high spectral resolution channel (HSRL) at 532 nm was added.

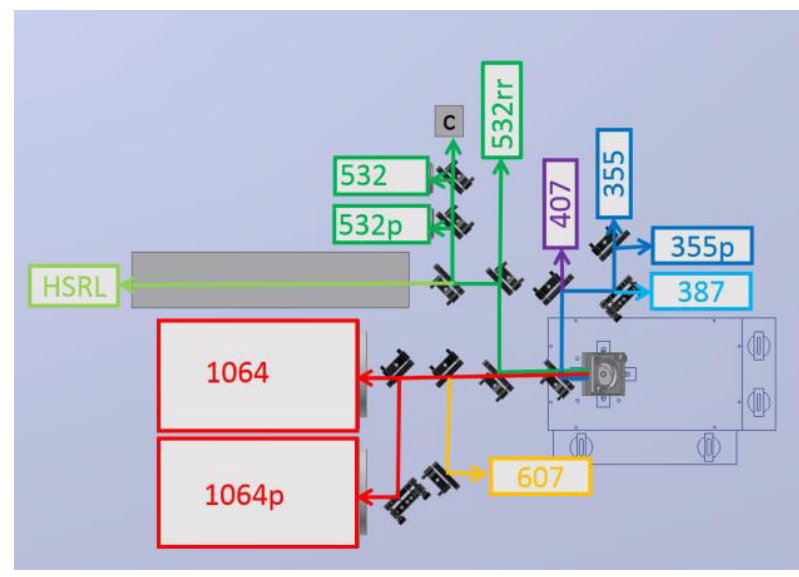

Figure 1 Sketch of the receiver unit of lidar system BERTHA with the three depolarization channels, labeled $\mathrm{p}$ (courteously of A. Klepel).

Two Nd:YAG laser (Continuum, Powerlite) transmit linearly polarized laser pulses at 355,532 and $1064 \mathrm{~nm}$. Two additional linear polarizers clean the polarization of the outgoing light. The repetition rate is $30 \mathrm{~Hz}$ and the pulse length $50 \mathrm{~ns}$. The pulse energy is $1.6 \mathrm{~J}$ (for $1064 \mathrm{~nm}$ ), $800 \mathrm{~mJ}$ (for $532 \mathrm{~nm}$ ) and $150 \mathrm{~mJ}$ (for $355 \mathrm{~nm}$ ). The beam is pointed to the sky under a zenith angle of $5^{\circ}$.

A $53 \mathrm{~cm}$ Cassegrain telescope collects the backscattered light. The receiver unit (see Fig. 1) separates the light into 13 detection channels: three elastic backscatter channels $(355,532$ and $1064 \mathrm{~nm})$ and three cross polarized elastic backscatter channels (355p, 532p and 1064p), two Raman channels (387 and $607 \mathrm{~nm}$ ), three rotational Raman channels (532rr), a water vapor channel at $407 \mathrm{~nm}$ and a HSRL channel at 532 $\mathrm{nm}$. All detectors are photomultiplier tubes (PMT) from Hamamatsu (H10721P-110). For the 1064 nm channels the PMTs R3236 from Hamamatsu are used. To reduce the signal noise, they are cooled down to lower than $-30^{\circ} \mathrm{C}$. In front of each cross polarized channel a linear polarizer perpendicular to the polarization of the laser beam is placed. To ensure the good quality of the depolarization measurements a $\Delta 90^{\circ}$ calibration (Freudenthaler et al., 2009) is performed for every measurement.

The signals are detected with a range resolution of $7.5 \mathrm{~m}$ and a time resolution of 5 to $30 \mathrm{~s}$. Table 1 summarizes the output of vertical profiles of the BERTHA system.

Table 1 Output of vertical profiles of the BERTHA system.

\begin{tabular}{|l|l|}
\hline Vertical profiles & Wavelength (nm) \\
\hline Particle backscatter coeff. & $355,532,1064$ \\
\hline Particle extinction coeff. & 355,532 \\
\hline Lidar ratio & 355,532 \\
\hline $\begin{array}{l}\text { Extinction and backscatter } \\
\text { Angström exponent }\end{array}$ & $355 / 532$ \\
$532 / 1064$ \\
\hline $\begin{array}{l}\text { Volume and Particle linear } \\
\text { depolarization ratio }\end{array}$ & $355,532,1064$ \\
\hline
\end{tabular}

A second lidar system POLIS (Portable Lidar System, contribution of V. Freudenthaler at the $27^{\text {th }}$ ILRC) from the Ludwig-MaximiliansUniversity, Munich, was deployed in the same campaign. It is a small portable 6-channel Raman and depolarization lidar system measuring the coand cross-polarized backscattered light at $355 \mathrm{~nm}$ and $532 \mathrm{~nm}$ (day- and night-time) and the $\mathrm{N}_{2}$ Raman shifted backscattered light at $387 \mathrm{~nm}$ and $607 \mathrm{~nm}$ (night-time only).

\section{MEASUREMENT EXAMPLE}

To give an example for the measurements of the depolarization ratio at three wavelengths the dust case of June 30, 2013 will be shown. It is a typical example for a strong dust event over the Western Caribbean. The Saharan dust plume was measured in parallel with the lidar systems BERTHA and POLIS, placed $30 \mathrm{~m}$ apart from each other, on Barbados during the SALTRACE campaign.

Figure 2 shows the range-corrected signal for the total and the cross polarized $1064 \mathrm{~nm}$ channel measured by the BERTHA system. The aerosol layer reaches up to $4.1 \mathrm{~km}$ about ground level. Combining the information of both channels the dust layer can be determined between about 1.8 $\mathrm{km}$ and $4.1 \mathrm{~km}$. It is characterized by a relative humidity of around $30 \%$. The layers beneath the dust layer are significantly more humid (around $80 \%$ ). The relative humidity is obtained by a radiosonde launched at 0000 UTC at the measurement site. 

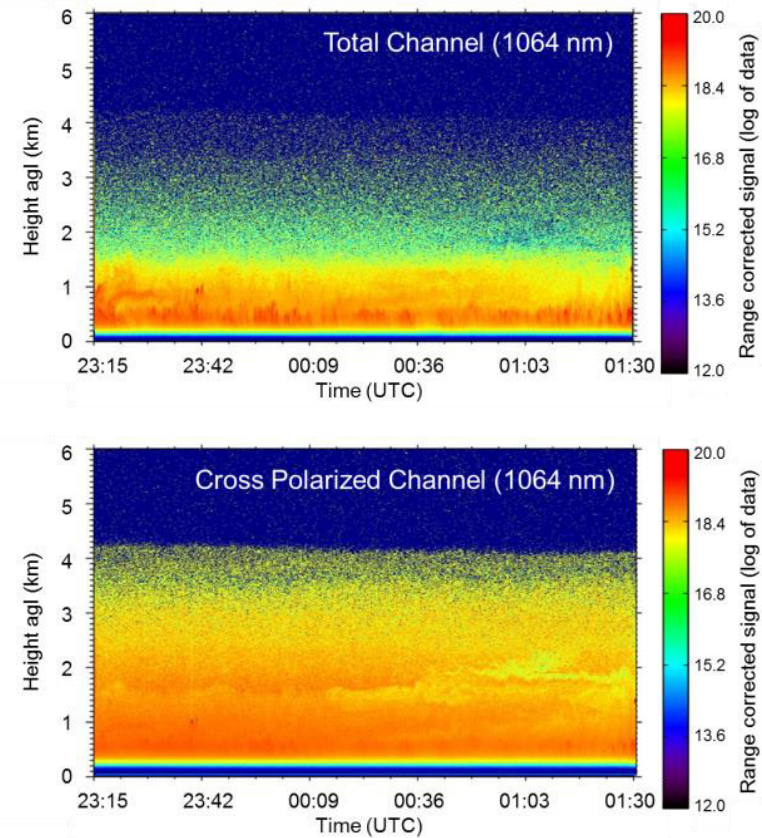

Figure 2 BERTHA measurement of 30 June 2013, 23:15, till 1 July 2013, 01:30 UTC, range-corrected signal for the 1064 $\mathrm{nm}$ total channel (upper part) and $1064 \mathrm{~nm}$ cross polarized channel (lower part). The first $500 \mathrm{~m}$ in these plots are note reliable due to high uncertainties in the overlap correction.

The atmospheric conditions remained almost constant over more than two hours (as it can be seen in Fig. 2). The retrieved profiles are averaged over this measurement period and shown in Fig. 3 for both lidar systems. The particle backscatter at 355 and $532 \mathrm{~nm}$ from BERTHA can be compared to the measurements obtained by POLIS and they agree very well. BERTHA measured additionally the particle backscatter at $1064 \mathrm{~nm}$, which reaches in the dust layer only about $70 \%$ of the particle backscatter at the other wavelengths. The particle extinction coefficient for BERTHA is determined via the Raman method (Raman channels at 387 and $607 \mathrm{~nm}$ ), for POLIS via the Fernald/Klett inversion with a fixed lidar ratio within the dust layer.

The measured lidar ratio within the transported dust layer $(1.8$ to $4.1 \mathrm{~km})$ is approximately $61 \mathrm{sr}$ and $71 \mathrm{sr}$ for the $355 \mathrm{~nm}$ and $532 \mathrm{~nm}$, respectively. For the Fernald-Klett algorithm a typical lidar ratio for dust of $55 \mathrm{sr}$ is taken.

The Ångström exponent yields to different values for backscatter and extinction, caused by different influence of the particle size distribution on these quantities. A lesser amount of large particles could be responsible for the lower backscatter at $1064 \mathrm{~nm}$.
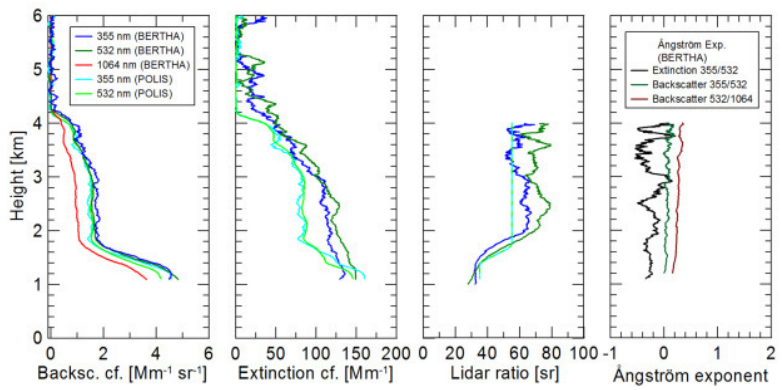

Figure 3 Vertical profiles for 30 June 2013, 2315 - 0130 UTC for the two lidar systems BERTHA and POLIS: the particle backscatter coefficient (100 m vertical smoothing), the particle extinction coefficient (750 m vertical smoothing), the lidar ratio (750 m vertical smoothing) and the Ångström exponent. BERTHA measurements are indicated in blue (355 $\mathrm{nm})$, dark green $(532 \mathrm{~nm})$ and red (1064 nm), POLIS measurements in cyan $(355 \mathrm{~nm})$ and light green $(532 \mathrm{~nm})$.

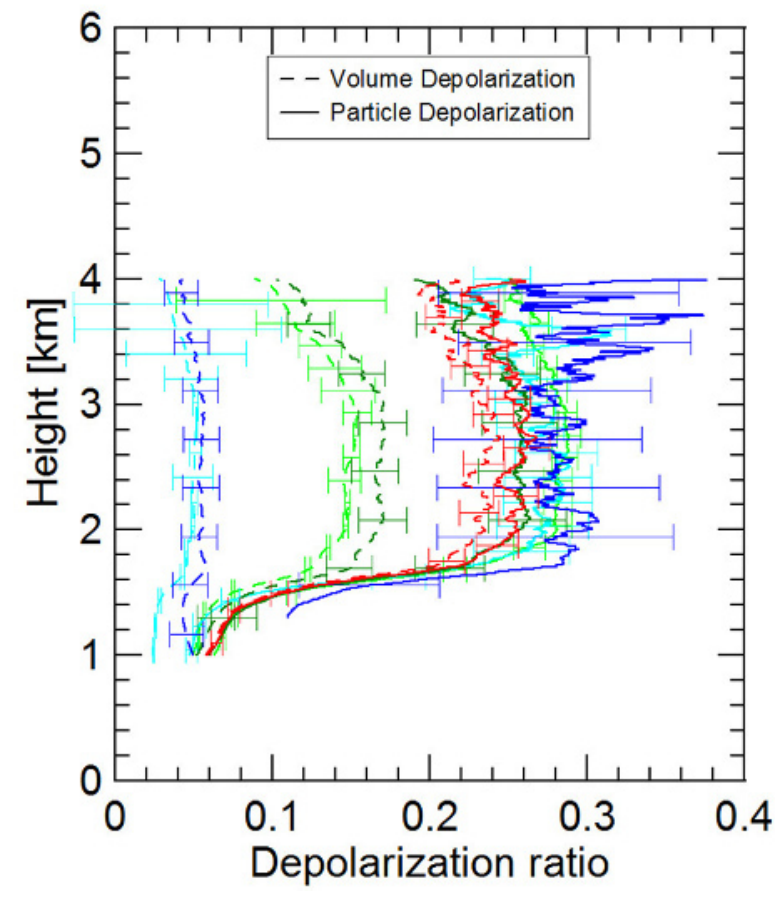

Figure 4 Vertical profiles of the depolarization ratio for 30 June 2013, 2315-0130 UTC. Colors for BERTHA and POLIS are the same as in Fig. 3, dashed lines correspond to the volume linear depolarization ratio, continuous lines to the particle linear depolarization ratio. The vertical smoothing length for the BERTHA measurements is $100 \mathrm{~m}$, for POLIS $190 \mathrm{~m}$.

BERTHA measured a particle linear depolarization ratio in the dust layer (1.8 to 4.1 $\mathrm{km}$ height) of $0.25 \pm 0.02$ for $532 \mathrm{~nm}$. This is slightly lower than the POLIS measurement $(0.27 \pm 0.01)$. For $355 \mathrm{~nm}$ the particle linear 
depolarization ratio agrees very well between BERTHA (0.27 \pm 0.07$)$ and POLIS (0.27 \pm 0.02$)$. For $1064 \mathrm{~nm}$ a particle linear depolarization ratio of $0.24 \pm 0.1$ can be reported.

\section{CONCLUSIONS AND OUTLOOK}

A method to measure the depolarization at three wavelengths simultaneously has been implemented and a unique data set of long-range transported Saharan dust has been recorded in two periods in summer 2013 and summer 2014 within the SALTRACE campaign. Furthermore pure marine conditions and dust, that had been mixed with biomass burning smoke over Western Africa and transported over the Atlantic Ocean, was measured in winter 2014 at Barbados. Dust-smoke mixtures will be shown at the conference as well.

The information, that can be obtained from the lidar ratio at two wavelengths (355 and $532 \mathrm{~nm}$ ), the Angström exponent for extinction and two backscatter ratios as well as the linear depolarization ratio at three wavelengths (355, 532 and $1064 \mathrm{~nm}$ ), consists of 8 vertically resolved parameters, which may serve as an input for more sophisticated aerosol classification schemes (Burton et al., 2012; Groß et al., 2013) and furthermore for the retrieval of microphysical properties of the aerosol particles. It will be also used to improve the modelling of dust particles (Gasteiger et al., 2011) and the separation of nondust, fine mode and coarse mode dust (Mamouri and Ansmann, 2014).

The measurement of the depolarization ratio at three wavelengths combined with Raman lidar measurements reveals a deeper look into the aerosol properties by means of remote sensing.

\section{REFERENCES}

[1] Heintzenberg, J, 2008: The SAMUM-1 Experiment over southern Morocco: Overview and introduction, Tellus Ser. B, 61, 2-11, doi: 10.1111/j.1600-0889.2008.00403.x.

[2] Ansmann, A., A. Petzold, K. Kandler, I. Tegen, M. Wendisch, D. Müller, B. Weinzierl, T. Müller, and J. Heintzenberg 2011: Saharan mineral dust experiments SAMUM-1 and SAMUM-2: What have we learned?, Tellus Ser. $B$, 63, 403-429, doi:10.1111/j.1600-0889.2011. 00555.x.
[3] Gasteiger, J and Freudenthaler, V, 2014: Benefit of depolarization ratio at $\lambda=1064 \mathrm{~nm}$ for the retrieval of the aerosol microphysics from lidar measurements, Atmos. Meas. Tech., 7, 37733781, doi: 10.5194/amt-7-3773-2014.

[4] Freudenthaler, V., Esselborn, M., Wiegner, M., Heese, B., Tesche, M., Ansmann, A., Müller, D., Althausen, D., Wirth, M., Fix, A., Ehret, G., Knippertz, P., Toledano, C., Gasteiger, J., Garhammer, M., Seefeldner, M., 2009. Depolarization ratio profiling at several wavelengths in pure saharan dust during samum 2006. Tellus 61B, 165-179.

[5] Freudenthaler, V., Seefeldner, M., Groß, S., Wandinger, U., 2015: Accuracy of linear depolarization ratios in clean air ranges measured with POLIS-6 at 355 and $532 \mathrm{~nm}$. Contribution to the $27^{\text {th }}$ ILRC, New York

[6] Burton, S. P., Ferrare, R. A., Hostetler, C. A., Hair, J. W., Rogers, R. R., Obland, M. D., Butler, C. F., Cook, A. L., Harper, D. B. and Froyd, K. D., 2012: Aerosol Classification of Airborne High Spectral Resolution Lidar Measurements Methodology and Examples, Atmos. Meas. Tech., 5, 73-98, doi:10.5194/amt-5-73-2012.

[7] Groß, S., Esselborn, M., Weinzierl, B., Wirth, M., Fix, A., and Petzold,A., 2013: Aerosol classification by airborne high spectral resolution lidar observations, Atmos. Chem. Phys., 13, 24872505, doi:10.5194/acp-13-2487-2013.

[8] Gasteiger, J., Wiegner, M., Groß, S., Freudenthaler, V., Toledano, C., Tesche, M., and Kandler, K., 2011: Modelling lidar-relevant optical properties of complex mineral dust aerosols, Tellus B, 63, 725- 741, doi:10.1111/j.1600-0889.2011.00559.x.

[9] Mamouri, R.E. and Ansmann, A., 2014: Fine and coarse dust separation with polarization lidar, Atmos. Meas. Tech., 7, 3717-3735, doi:10.5194/ amt-7-3717-2014 